\title{
Consumer Recall of Brand Versus Product Banner Ads
}

\section{Authors: Eric Van Steenburg}

This is a postprint of an article that originally appeared in Journal of Product \& Brand Management on September 14, 2012. The article can be found here, http://dx.doi.org/10.1108/10610421211264937.

Eric Van Steenburg, (2012) "Consumer recall of brand versus product banner ads", Journal of Product \& Brand Management, Vol. 21 Issue: 6, pp.452-464, doi: 10.1108/10610421211264937

Made available through Montana State University's $\underline{\text { ScholarWorks }}$ scholarworks. montana.edu 


\title{
Consumer recall of brand versus product banner ads
}

\author{
Eric Van Steenburg \\ Department of Marketing \& Logistics, University of North Texas, Denton, Texas, USA
}

\begin{abstract}
Purpose - The paper aims to determine the effectiveness of specific online advertisements, comparing banner ads that are brand-reinforcing versus ones that are product-reinforcing.

Design/methodology/approach - The research uses three experimental design studies to empirically test the hypotheses based on the elaboration likelihood model (ELM) by manipulating type of online banner advertisement (brand-type versus product-type) and measuring individual need for cognition (NFC).

Findings - Consumers high in NFC recall product-type banner ads more readily than those low in NFC, while brand-type banner ads are more likely to be recalled by low-NFC consumers. However, high-NFC consumers recall brand-type ads under all situational influences tested. And while consumers low in NFC recall product-type banner ads featuring a directive better than their high-NFC counterparts, they do not recall directive ads at a greater rate than high-NFC consumers recall brand-type ads.

Research limitations/implications - While previous research has found that variations in ad size, color, interactivity, and web site location affect recall, this research only measured static banner ads that appear at the top of the page. However, because it is the first to examine involvement in terms of NFC in combination with brand- and product-type ads, the research sheds new light on consumer awareness of two types of banner ad strategies adopted by marketing managers today.

Practical implications - In an online context, the type of banner ads used by marketing managers should be paired with the web site based on how much time consumers spend at the site and how many pages they click through at the site. All things being equal, however, managers should favor brand-type banner ads over product-type banner ads.

Originality/value - The research extends understanding of ELM as it relates to type of banner ad while establishing a potential research stream for better understanding of how consumers process various types of online ads. At the same time, it provides new evidence that can help marketing managers make better strategic decisions regarding their online marketing mix.
\end{abstract}

Keywords Online advertising, Banner advertisements, Advertisement recall, Brands, Memory, Brand awareness

Paper type Research paper

An executive summary for managers and executive readers can be found at the end of this article.

\section{Introduction}

Marketers include brand awareness and brand recognition as two of their top objectives for their online marketing efforts (Hollis, 2005). However, firms who advertise online, their marketing managers, and the web sites that host their advertisements still operate under the concept that online advertisements must be measured by click-through rate (CTR), that is, the percentage of visitors to a web site in which the ad was displayed who click on the ad (Yoo, 2009), and therefore follow a cost-per-click model of advertising expenditures (BusinessWeek, 2007). If the function of online advertising is to influence people just as marketers do now when advertising in print or broadcast (Drèze and Hussherr, 2003), then the focus should be on the brand rather than sales. Recognition and awareness of the brand can be developed even if consumers are not clicking on the banner ad (Briggs and Hollis, 1997) and have been shown to have potential for branding whether or not consumers recall seeing the ad (Yoo, 2009).

Unfortunately, CTR cannot measure awareness or recognition of a brand, and arguments have been put forth suggesting that online ads be measured by other means such as behavioral intention or message recall (Briggs and Hollis, 1997; Drèze and Hussherr, 2003). Recall and recognition, among the most prevalent forms of advertising measurement for offline advertisements, have also been used to measure online ads and been found to be positively related to attention given to the ad and purchase intention, but not brand attitude (Goodrich, 2011). This leaves practitioners to play a guessing game in terms of online advertising strategy as they choose between one designed to generate CTR, and one that would be better measured by recall and recognition.

This study focuses on the question of whether to adopt an online advertising strategy that relies on product-type banner ads that should be measured by CTRs, or brand-type banner 
ads that should be measured by recall and recognition. To do so, three experiments were conducted that evaluate the effectiveness of different types of online ads based on the elaboration likelihood model (ELM) and an individual's need for cognition (NFC). The paper concludes with implications for researchers and marketing managers that could change the way managers approach their online advertising strategy.

\section{Background}

The question of whether online advertisements should be measured by CTR or a behavioral response, such as purchase intention or message recall, is essentially a debate to determine if online ads should be designed for and measured by direct response (Pharr, 2004) or designed for branding purposes and measured using appropriate brand metrics (Broussard, 2000; Yoo, 2009). In support of a strategy to generate a direct response from the consumer, research shows advertisements representing online companies have a higher CTR than companies with both an online and physical presence, and may actually under-represent the impact on sales (Chandon et al., 2003). In addition, some argue that research on banner ads using CTR as the empirical measurement record voluntary behavior in a realistic environment, thus eliminating researcher bias (Baltas, 2003; Cho, 2003; Pharr, 2004).

However, measuring online ads using metrics reserved for brands provides "a more relevant measure of advertising effectiveness than CTR with advertisers who seek to use the online medium for more traditional brand building, and for which direct response is a desirable but unlikely result," (Hollis, 2005, p. 257). Moreover, data can be "highly skewed" if few of the banner ads tested obtain relevant CTRs (Robinson et al., 2007, p. 532).

If, however, the function of online advertising is to support a company or product brand, as researchers have suggested (Briggs and Hollis, 1997; Drèze and Hussherr, 2003; Yoo, 2009), then empirical evidence more appropriate for measuring brands must be gathered to support this claim. Because cued recall is dependent on a consumer's ability to recall a brand name from memory (MacInnis et al., 1999), successful online brand advertising campaigns must be associated to existing branding efforts that have established brands and their images into consumer memories. Therefore, just as brand images must be designed to facilitate recall of the cue from memory, so too must online ads be designed to take advantage of the brand images. If marketers leverage existing brand images as the cue to online brand advertising activities, consumers should be able to recall online ads designed to support the brand. However, research has also shown that images of products have an effect on awareness of online ads (Luk et al., 2002).

As one can see, there is debate over the purpose of banner advertisements and how to measure their effectiveness, leading to confusion for practitioners as they develop their online advertising strategy. In an effort to shed additional light on these issues, the following questions will be investigated in this research:

- How well do consumers recall online ads designed to support a brand versus online ads designed to support a product?

- Do consumers recall one type of online ad more frequently than another?
- What strategies should marketing managers adopt when it comes to developing and implementing online advertisements?

To answer these questions, this research relies on the elaboration likelihood model (ELM) as its theoretical foundation, and three $2 \times 2$ between subjects, full-factorial designs.

\section{Theory and hypotheses}

According to ELM, individuals process persuasive information differently (Petty and Cacioppo, 1981); and in regard to marketing communications, that processing begins the moment they receive a firm's message. Processing proceeds on one of two routes - central or peripheral depending on factors such as message content, inherent traits of the consumer, and the situation in which the consumer finds himself or herself (Cialdini et al., 1981). Consumers follow the central route to persuasion when high-involvement information processing takes place, and the peripheral route when the consumer is involved in low-involvement information processing (Petty and Cacioppo, 1981). Individuals engaged in high-involvement processing pay attention to the message more carefully than their lowinvolvement counterparts. When high-involvement processing takes place, consumers compare the incoming message to their own existing attitudes and generate one or more cognitive responses (Cialdini et al., 1981), from which beliefs, attitudes, and behavior can change based on how well these cognitive responses align with the message being communicated (Petty et al., 1983). When it comes to consumer response to advertising, different persuasive methods work depending on whether the elaboration likelihood of the communication situation is high or low (Petty et al., 1983), making quality of the argument in the message critical (Cacioppo et al., 1983). In other words, individuals are more likely to expend cognitive effort in evaluating a message or product when message involvement is high rather than low (Petty et al., 1983).

Even consumers engaged in low-involvement persuasive message processing are generating cognitive responses to the stimulus, albeit using peripheral cues to accept or reject the message and having little effect on attitude and behavior. Therefore, researchers measure an individual's need for cognition (Cohen et al., 1955) in an attempt to predict consumer behavior. Need for cognition (NFC) refers to an individual's tendency to engage in and enjoy effortful cognitive endeavors (Cacioppo et al., 1996), measures the inherent trait that consumers have to engage in problem solving activities (Peltier and Schibrowsky, 1994), and is related to an individual's tendencies to seek and engage in effortful cognitive activity and enjoy cognitively effortful circumstances (Cacioppo et al., 1996). NFC is also related positively to being open minded and general intelligence, and is effective in measuring attitudes toward simple or complex versions of a cognitive task (Cacioppo and Petty, 1980).

Individuals regularly exhibit high-NFC or low-NFC characteristics (Haugtvedt et al., 1992) in which high-NFC individuals require more information than their low-NFC counterparts and therefore follow the central route of persuasive information process. These individuals have a need to examine the quality of the argument in the message, 
and will process more complex messages (Cacioppo et al., 1983). NFC has an effect on message elaboration, motivation to process information, attitude change, message persuasiveness, and message recall (Haugtvedt and Petty, 1992), and has been shown to be a good determinant of advertising effectiveness in a web environment based on consumer goal-directedness and involvement (Wang et al., 2009).

This theoretical foundation - that high-NFC consumers have a higher level of involvement in the ad's message than low-NFC consumers (Petty et al., 1983), and that producttype ads in which the argument of the message is more complex appeals to high-NFC individuals as opposed to brand-type ads with a more simplistic message that appeals to low-NFC individuals (Cacioppo et al., 1996) - provides the basis for this research. Taken in concert with recent research that indicates that consumers pay attention to an online ad based, among other factors, on ad type (Goodrich, 2011), it stands to reason that the interaction of advertisement type and need for cognition will create a significant predictor of online advertisement recall.

Furthermore, if high-NFC consumers have a tendency to recall complex messages better than low-NFC consumers, and low-NFC consumers recall simple messages better than high-NFC consumers (Cacioppo and Petty, 1980), then measuring an individual's NFC level in conjunction with measuring recall in an online advertisement environment should provide a level of effectiveness of the type of ad. And because product-type ads are designed with more complex arguments than brand-type ads designed to support an image through use of elements such as logos and taglines, the following hypothesis is proposed:

H1. Consumers high in need for cognition will recall product-type banner ads at a greater rate than they will recall brand-type banner ads, while consumers low in need for cognition will recall brand-type banner ads at a greater rate than they will recall product-type banner ads.

Because high-NFC individuals require more information and pay attention to the message more carefully than their lowinvolvement counterparts (Cacioppo et al., 1983), they are more likely to expend cognitive effort in evaluation when message involvement is high rather than low (Petty et al., 1983). Therefore, even brand-type banner ads generate cognitive responses to the stimulus in high-NFC consumers, meaning:

H2. Consumers high in need for cognition will recall brand-type banner ads at a greater rate than consumers low in need for cognition will recall product-type ads.

Repeated exposure to the same banner advertisement increases recall, recognition, and intention rates (Chatterjee, 2005; Yaveroglu and Donthu, 2008). A consumer experiences advertising repetition when he or she is simply exposed to the ad multiple times, with level of exposure ranging from a low of two exposures to establish brand recognition (Tsao, 2010) to a recommended practitioner high of 60-100 repetitions per month (Pérez-Gladish et al., 2010). With traditional media, repeated ad exposure increases the likelihood that a brand name will be remembered and improves the effectiveness of the ad (Burke and Srull, 1988; Cacioppo and Petty, 1979; Unnava and Burnkrant, 1991), but attention and effectiveness decrease as the number of exposures increases (Pieters and Warlop, 1999) with peak effectiveness after just two or three exposures (Krugman, 1972).

In an online environment, banner ad repetition leads to greater brand name memory and click-through intention (Yaveroglu and Donthu, 2008), and recognition increases with high repetition of the same ad, regardless of the execution, in a goal-directed condition (Chatterjee, 2005). However, repetition of some banner ads can lead to negative consumer responses at a faster rate than traditional advertising, and CTR declines with repetition (Chatterjee et al., 2003). Based on these findings, and in conjunction with ELM and NFC:

H3. Under multiple exposures, consumers high in need for cognition will recall product-type banner ads at a greater rate than they will recall brand-type banner ads, while consumers low in need for cognition will recall brand-type banner ads at a greater rate than they will recall product-type banner ads.

Knowing that individual differences in NFC are related to an individual's tendencies to seek and engage in effortful cognitive activity and enjoy cognitively effortful circumstances (Cacioppo et al., 1996), and that high-NFC consumers are more likely to expend cognitive effort in evaluating a message when involvement with the message is high (Petty et al., 1983), it is posited that:

H4. Under multiple exposures, consumers high in need for cognition will recall brand-type banner ads at a greater rate than consumers low in need for cognition will recall product-type ads.

Previous research has also demonstrated that specific elements of an online banner ad can affect individuals differently (Danaher and Mullarkey, 2003; Robinson et al., 2007), specifically promotional offers and incentives (Hupfer and Grey, 2005; Robinson et al., 2007), as well as specific directives such as "click here" have been shown to increase recall (Danaher and Mullarkey, 2003; Hupfer and Grey, 2005). However, it not been empirically tested whether or not a "click here" directive in a banner ad is processed centrally or peripherally. Because it is additional information appearing in the ad, one could argue that ELM supports "click here" as central processing conducted by those high in NFC. However, because it is not specifically part of the product information set, it could also be argued that such messages are processed peripherally, and advertisements featuring directives are more likely to be recalled by low-NFC consumers. Because research has shown that argument quality has a greater effect in terms of recall among individuals high in NFC than those low in NFC (Cacioppo et al. 1983), and directives are not specifically supporting the argument of the message, but rather are associated elements of the advertisement not related specifically to a product, it is hypothesized that:

H5. Consumers high in need for cognition will recall brand-type banner ads at a greater rate than they will recall product-type banner ads with directives, while consumers low in need for cognition will recall product-type banner ads with directives at a greater rate than they will recall brand-type banner ads. 
If directives in banner ads are processed peripherally, and NFC has an effect on message elaboration, motivation to process information, and message recall (Haugtvedt and Petty, 1992), it stands to reason that high-NFC individuals will pay more attention to brand-type ads than their low-NFC counterparts pay attention to directives. Therefore:

H6. Consumers high in need for cognition will recall brand-type banner ads at a greater rate than consumers low in need for cognition will recall product-type ads with directives.

Three studies test how well consumers recall online ads designed to support a brand versus online ads designed to support a product, as well as whether or not consumers recall one type of online ad more frequently than the other.

\section{Study 1: consumer propensity to recall specific banner ads}

Study 1 tests $H 1$ and $H 2$ by measuring whether or not the type of online advertisement used in a banner ad has an effect on advertisement recall based on a consumer's propensity for message processing. It is also designed to determine if product-type or brand-type banner ads generate greater recall, and what strategies marketing managers might adopt for each type of ad.

\section{Study 1: method}

Manipulations requiring extensive and relevant thought have a greater impact when message processing involvement increases because they lead the individual to consider the argument related to the issue or product (Petty et al., 1983). On the other hand, manipulations that require evaluation without engaging in extensive thinking have a greater impact when message involvement is low rather than high (Petty et al., 1983). Based on that, experimental design was the basis for this study, and two types of banner advertisements were developed - one image-based requiring low message involvement which could be used to support a brand, and one information-based requiring high message involvement which could be used to support a product. The product- and brand-type ads were developed based on three criteria:

1 Level of complexity of the ad, which has been found to be effective in measuring attitudes toward a cognitive task (Cacioppo and Petty, 1980).

2 Research findings that identify what marketing communication vehicles are the most salient visual brand element for consumers (Mininni, 2005) to create brand-type ads.

3 Common practices among firms using banner ads today to promote product features, such as the one for BMW found at the top of the Internet Movie Database homepage (www.imdb.com), a popular consumer web site, at the time of the study (see Figure 1).
Three well-known global brands - Apple, Lexus, and Nike were chosen from Interbrand's report of the top global brands (Interbrand, 2010). At the time of the study, Interbrand ranked Apple 20th, Nike 26th, and Lexus 96th on the list of the top 100 global brands. According to Interbrand, a brand qualifies as global if it:

- transcends geographic and cultural differences;

- has expanded across the established economic centers of the world;

- at least 30 percent of revenues come from outside the country of origin but no more than 50 percent from any one continent;

- has a presence in at least three major continents;

- profits are positive; and

- the brand has a public profile and awareness above and beyond its own marketplace (Interbrand, 2010).

By relying on Interbrand's report of the top 100 brands, which requires brands to meet the aforementioned criteria, and eliminating any brand logos that contained the name or initials of the brand (e.g. Intel, IBM, BMW) that would make ease of recognition a potential confound, the pool of three brands used in the research represents ones that would be well-known across a wide variety of sociographic, demographic, and consumer groups. Both types of ads were developed for each company, creating a total of six unique ads. To maintain consistency between advertisements, each ad featured text on the left side of the banner and an image on the right side, resembling the banner ad previously mentioned found at the top of the Internet Movie Database homepage (www.imdb.com) at the time of the study.

Because color, size, location, and animation have been found to affect banner ad effectiveness (Hong et al., 2004; Robinson et al., 2007; Yoo and Kim, 2005; Yaveroglu and Donthu, 2008) all ads were designed without color or animation, and each banner was the same size and placed in the same location throughout the duration of the research. For the brand-type ads, the left side of the banner contained the company or product tagline and the right side contained the company or product logo. Logos were chosen because these graphic elements are what a company uses to identify itself and its products (Henderson and Cote, 1998), act as a corporate identifier (Dowling, 1994; Baker and Balmer, 1997; Olins, 1989), and help create an organization's identity (Abimbola, 2009). In addition, logos are a mainstay of a variety of marketing communication vehicles, and have been found to be the most salient visual brand element for consumers (Mininni, 2005).

The advertisements were intentionally kept simplistic (few elements, limited wording, clean lines, etc.) and static (no movement, consistent location, no interaction required) because, with the exception of some animation, artistic execution overall had little effect on CTR or memory-based measures (Drèze and Hussherr, 2003) and intrusiveness is not a mediator in recall of online advertisements (McCoy et al., 2008). Instead, factors found to influence online ad recall

\section{Figure 1}

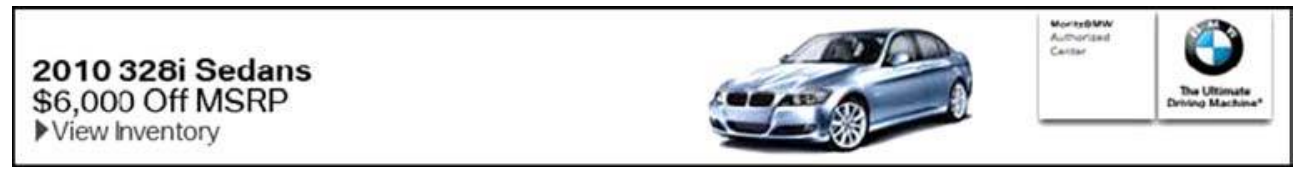


include viewing mode, duration of page viewing, and web page context, including text and page complexity, and ad style (Danaher and Mullarkey, 2003). To test whether or not ad type has an effect on recall of the ad in an online environment based on high and low consumer involvement, product-type advertisements were developed to counter the brand-type ads. The product-type ads contained text describing a specific product on the left side, while the right side featured an image of the product. Research indicates that including pictures in online ads made them more attractive (Luk et al., 2002).

\section{Study 1: participants}

The online questionnaire was started by 151 participants, though four were eliminated because they did not complete the entire questionnaire, and two were eliminated for providing repetitive answers throughout the survey. Of the 145 (96.0 percent) respondents who completed the questionnaire, 114 were female (78.6 percent) and the age range was 18 to $56(M=26.24)$. Responses were gathered online from undergraduate and graduate students at two universities in the Southwest United States. All undergraduates were allowed to participate in exchange for course extra credit.

\section{Study 1: measures}

Advertising recall (dependent variable) was measured three times per respondent in unaided, partially aided, and fully aided situations over the course of questionnaire. Following the procedure of Drèze and Hussherr (2003), data on the first dependent variable, unaided recall, was gathered by asking respondents whether or not they recalled seeing a banner ad while reading the story on a web site about a current event. If they responded "yes" a follow-up, open-ended question was administered allowing them to input the name of the companies or brands they recalled seeing. If they answered "no" the respondent skipped the open-ended follow-up question. Again following the procedure of Drèze and Hussherr (2003), participants were then shown a list of 12 companies or brands containing the three companies or brands being tested in this study, and were asked to indicate which of the 12 they "knew or had heard of." The same list was presented a second time and respondents were asked to indicate which of the 12 they believed they could "identify the logo." Finally, to measure partial recall, respondents were shown the same list of 12 a third time and were asked to indicate which of them they "recall seeing a banner ad while looking at the web pages in this survey." Responses to this final question in terms of number of companies recalled were recorded as the second dependent variable (partially aided recall).

To measure fully aided recall, respondents were then shown the three banner ads, one at a time, which corresponded to the ad type to which they had been previously exposed (Drèze and Hussherr, 2003). The order of the banner ads was randomized so that the ads did not appear in the same order in which respondents had seen them while viewing the web pages. After viewing each banner ad, respondents were asked if they recalled seeing that advertisement. Those who answered affirmatively were given a follow-up question asking them to identify the company or brand in the ad. Replicating the methodology of Drèze and Hussherr (2003), the name of the company or brand was blocked out for respondents who previously saw the product-based ads so as not to provide additional cues to their identification.

Independent variables were advertisement type and NFC. To manipulate ad type, participants were randomly assigned to either brand-type or product-type banner advertisements, and randomization was also used to ensure respondents were exposed to advertisements for the three companies - Apple, Nike and Lexus - in a different order no matter which ad type they saw. NFC was measured on a seven-point Likert-style 18-item scale (Cacioppo et al., 1984). To account for preexisting attitudes toward the three brands, respondents completed a nine-item attitude toward the brand (ATB) scale (Peracchio and Meyers-Levy, 1994) composed of various semantic differentials used to measure consumer's evaluation of a brand. The scale was contextualized to the three companies/brands used in this study.

\section{Study 1: procedure}

A 2 (ad type: brand vs product) x 2 (NFC: high vs low) between-subjects full-factorial design was implemented. Because consumers do not visit information sites on the Internet to look at ads, but rather to search for information on a topic of their interest (Rodgers and Sheldon, 2002; Yoo, 2007), an online questionnaire was developed to simulate a consumer using the internet to search for information. Respondents were first told the experiment was being conducted to measure the effectiveness of news web sites rather than online advertising recall, and were given a paragraph to read relating to a current event in the news. The initial paragraph read:

WASHINGTON, D.C. - In the wake of a growing scandal and the largest car recall in automotive history, Toyota announced today it is considering firing its long-time CEO, Akiro Toyoda, the grandson of the company founder. Should the world's largest automaker fire Toyoda, it would mark the first time in company history that a member of the family was not at the helm.

Next they were told their reading comprehension would be tested after they visited three web pages that provided more information about the current event. Respondents were then presented three consecutive images of a web page from a wellknown news network that featured a photograph and an introduction to a story about the current event on the first page followed by a continuation of the story on the subsequent pages. One banner ad of each company was placed on top of each page, meaning that respondents only saw one banner ad for each company one time. The combination of web page and banner ad was randomized so that respondents saw banner ads in random order. However, respondents only saw one type of banner ad - either the brand-type or the product-type.

After the third web page, and to ensure participants were engaged in the web sites in a typical information-gathering mode, respondents were asked three reading comprehension questions about the news story. Following the reading questions, participants were given a series of filler questions asking their opinions about online news sites and their Internet-use behavior. The independent variable NFC was then measured, followed by the dependent variables of unaided, partially aided, and fully aided recall. Attitude toward each of the three brands was measured next, before demographics were captured. 


\section{Study 1: results}

An analysis of the comprehensive reading questions showed 137 participants (94.5 percent) answered the first question correctly (i.e. identified the source of the news story), 119 (82.1 percent) answered the second correctly, and 57 (39.3 percent) answered the third question correctly. The high percentage of correct answers on two of the three comprehensive reading questions demonstrates that the simulation achieved its desired result of placing respondents in a situation that mirrored reality.

Construct reliability was measured for the NFC scale, as well as the three measurements of ATB for each individual company or product. Cronbach's alpha for NFC $(\alpha=0.864)$, $\mathrm{ATB}_{\text {Apple }}(\alpha=0.858), \mathrm{ATB}_{\text {Lexus }}(\alpha=0.890)$ and $\mathrm{ATB}_{\text {Nike }}$ ( $\alpha=0.909$ ) demonstrated each construct is highly reliable (Hair et al. 2006). The results of the dependent variable (advertising recall) were analyzed using full factorial, between-subjects MANCOVA. A median split was performed to divide participants into high- and low-NFC groups according to their scores on the NFC scale $(M=4.664, M d n=4.556)$. Recall was based on the raw scores of how many of the three company/product/brand names respondents recalled accurately (Danaher and Mullarkey, 2003). This procedure was followed for the unaided, partially aided, and fully aided raw scores, as well as combined for an overall recall total per participant.

The main effects for NFC and ad type were not significant ( $p$ s $>0.10)$ for overall recall total or unaided, partially aided, or fully aided recall. However, the multivariate test for the interaction between NFC and ad type was marginally significant (Wilks' Lambda $F(3,137)=2.402, p=0.07$ ), and the covariate attitude toward the brand was significant $(p=0.05)$. The between-subjects test of the interaction between NFC and ad type was significant (see Figure 2) for unaided recall $(F(1,139)=6.608, p=0.01)$ as high-NFC consumers recalled the product-type advertisements at a higher rate than low-NFC consumers $\left(M_{\text {high }}=2.00\right.$ $\left.M_{\text {low }}=1.52\right)$ while low-NFC consumers recalled the brandbased ads better than high-NFC consumers $\left(M_{\text {high }}=1.53\right.$ $M_{\text {low }}=1.74$ ). Overall recall total (see Figure 3 ) was also marginally significant $(F(1,139)=2.681, p=0.10)$ with

Figure 2

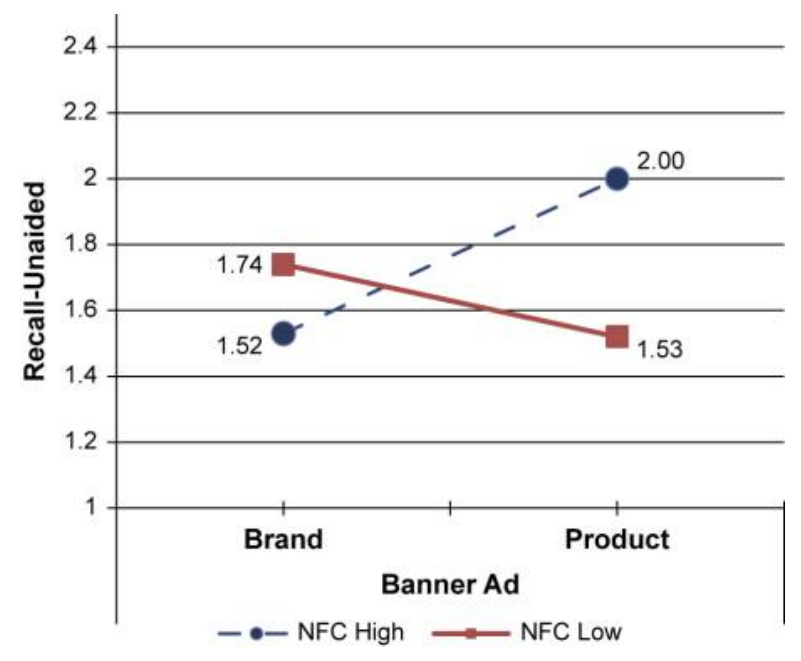

Figure 3

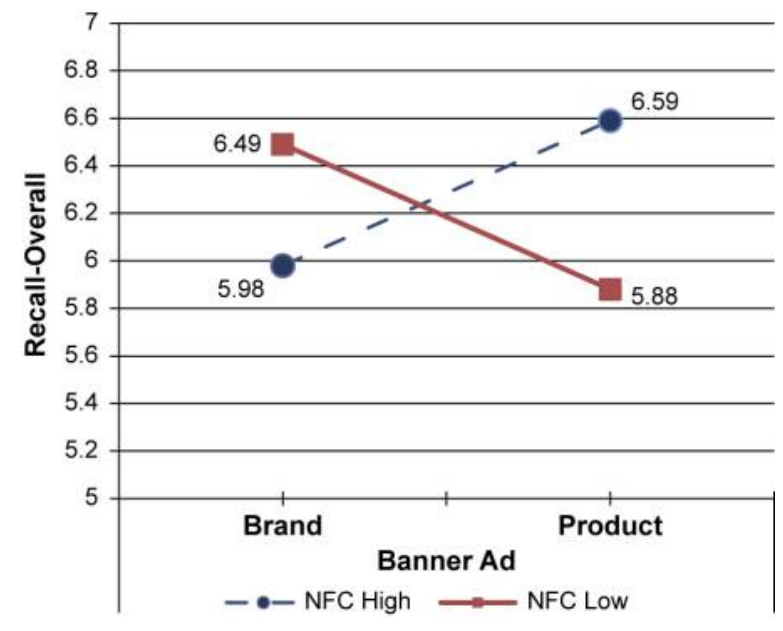

high-NFC consumers recalling product-type ads at a greater rate $\left(M_{\text {high }}=6.59 M_{\text {low }}=5.88\right)$ and low-NFC consumers recalling brand-type at a greater rate $\left(M_{\text {high }}=5.98\right.$ $\left.M_{\text {low }}=6.49\right)$. The results overall support $H 1$. While there was no significance for the partially aided and fully aided recall, results were consistent in that high-NFC consumers always had a greater mean than low-NFC consumers when it came to product-type ad recall, while low-NFC consumers recalled the brand-type ads more often. Finally, in testing $\mathrm{H} 2$, an independent-samples T-test was conducted on high-NFC consumers who saw the brand-type banner ads, and low-NFC consumers who saw the product-type ads. While means for the two groups provided directional support for $H 2$, results for each of the recall situations were not significant.

\section{Study 1: discussion}

The data yield interesting results for the effects of ad type and individual differences in message processing on banner ad effectiveness. The fact that recall was significant only when the two independent variables (NFC and ad type) worked in combination and not independently indicates that not only are these processes functioning in tandem, thus making the results even more robust (Barron and Kenny, 1986), but that marketers have an opportunity to leverage this information in real time while consumers are visiting their site. This has implications for both theory development and marketer implementation. For the former, NFC was verified as a moderator for online persuasive communications, thus expanding the scope of the ELM model. The study found that high-NFC consumers recalled complex messages more easily after only a few cues, while brand-type online advertisements are more readily recalled by low NFC consumers after they are provided more cues to the ad.

For practitioners, the results indicate the importance of an online message strategy that matches consumers' efforts to seek and engage in cognitive activity with the type of banner ad they are shown. For example, because high-NFC individuals recalled brand-type banner ads at a slightly greater rate than low-NFC individuals recalled product-type banner ads, placing brand-type ads on the first page or two that a consumer visits would have greater recall affects than a product-type ad. Therefore, it may be more appropriate for a 
firm to place a brand-type banner ad on the home page where all customers visit, but begin to display product-type banner ads the more pages a customer visits based on the fact that these consumers are likely be higher in cognitive activity. A more detailed discussion of this is provided in the section on implications.

\section{Study 2: consumer propensity to recall banner ads after repetition}

Because previous research has shown that repeated viewings of an advertisement affects recall (Chatterjee, 2005; Yaveroglu and Donthu, 2008), Study 2 was developed to test whether these finding are consistent for different types of banner ads (product vs brand) when an individual's message processing is taken into account. Study 2 tests $H 3$ and $H 4$.

\section{Study 2: participants}

An online questionnaire was completed by 131 respondents, though 1 was eliminated for failing to follow directions. Of the 130 respondents, 84 were female ( 64.6 percent) and the age range was 19 to $43(M=24.12)$. Responses were gathered online from undergraduate students at a university in the Southwest United States in exchange for course extra credit.

\section{Study 2: procedure}

Following the same methodology as Study 1 and Drèze and Hussherr (2003), the dependent variable (advertisement recall) was measured in unaided, partially aided, and fully aided situations. The independent variables (NFC and ad type) were also manipulated similarly to Study 1 . As was the case in Study 1, a 2 (ad type: brand vs product) x2 (NFC: high vs low) between-subjects full-factorial design was used. Participants in the second study were given a cover story that the intent of the study was to evaluate online news sites, just as respondents had been in Study 1, and read the same initial paragraph before proceeding to the web pages.

Participants saw three consecutive images of the same wellknown news site web pages as they did in the first study with one banner ad at the top of each page. However, rather than seeing one banner ad for each company (Nike, Apple, Lexus), Study 2 adopted Krugman's (1972) three sequential advertising exposures approach, so that participants saw the same banner ad at the top of each of the three pages. The combination of web page and banner ad was randomized so that overall the company ads were evenly distributed. As was the case in the first study, respondents saw either a producttype or a brand-type banner ad.

In replicating Study 1, respondents were asked a series of reading comprehension questions about the new story after viewing the third web page. Finally, participants saw the same filler questions as the previous study, before completing the NFC scale and the unaided, partially aided, and fully aided recall measures. Attitude toward the brands was measured, followed by demographics.

\section{Study 2: results}

In analyzing the reading comprehension questions, 125 participants (96.5 percent) answered the first question correctly, 111 (85.4 percent) answered the second correctly, and 50 (38.6 percent) answered the third correctly, demonstrating that the simulation placed respondents in a situation that mirrored reality. Construct reliability for NFC $(\alpha=0.886), \operatorname{ATB}_{\text {Apple }}(\alpha=0.921), \operatorname{ATB}_{\text {Lexus }}(\alpha=0.902)$ and $\mathrm{ATB}_{\mathrm{Nike}}(\alpha=0.858)$ demonstrated each is highly reliable (Hair et al., 2006). As in Study 1, the results of the dependent variables were analyzed using full factorial, between-subjects MANCOVA and a median split was performed to divide participants into two groups according to their NFC $(M=4.678, M d n=4.667)$. Again, recall was based on the raw scores of how many of the three advertisement names respondents recalled accurately for unaided, partially aided, and fully aided recall, as well as combined for a recall total.

Recall total was not significant for the main effect nor the interaction ( $p$ s $>0.10$ ), providing no support for $H 3$. The covariate (ATB) also was not significant. Though just as in the first study and as expected, high-NFC consumers in Study 2 recalled product-type ads at a greater rate than low-NFC consumers $\left(M_{\text {high }}=6.295, M_{\text {low }}=6.256\right)$. But, unlike Study 1 in which low-NFC consumers recalled brand-type ads at a greater rate than their high-NFC counterparts, when shown the same brand-type ad multiple times, the high-NFC consumers had a greater recall rate than low-NFC consumers $\left(M_{\text {high }}=6.256, M_{\text {low }}=5.984\right)$. In fact, recall of brand-type banner ads for high-NFC consumers was almost the same as it was for their recall of product-type ads $\left(M_{\text {product }}=6.295, M_{\text {brand }}=6.256\right)$. Low-NFC consumers recalled product-type ads more often than high-NFC consumers in unaided and fully aided situations, but not when partially aided. High-NFC consumers recalled brandtype ads at a greater rate than low-NFC consumers in all aided situations. In testing $H 4$, it was discovered the mean for high-NFC consumers' recall of brand-type ads was equal to that of low-NFC consumers recall for product-type ads $(M=6.256)$. An independent-samples T-test confirmed results were not significant, therefore $H 4$ was not supported.

\section{Study 2: discussion}

Although individuals high in NFC still recalled product-type banner ads more readily than their lower NFC counterparts, Study 2 found some evidence that high-NFC consumers also recall brand-type banner ads more readily under repeated viewing of the same ad. A possible explanation for these results may be found by comparing the means of brand-type banner ad recall by the high-NFC individuals from Study 1 $(M=5.988)$ to those from Study $2(M=6.256)$, in which recall of brand-type banner ads increased under repetition. According to ELM, increased message processing can be attributed to increased involvement because individuals are more likely to expend cognitive effort in evaluating a message or product when message involvement is high rather than low (Petty et al., 1983). Because situational involvement is a factor that determines message processing (Cialdini et al., 1981), it is likely that the repeated advertisements increased the level of situational involvement of the participants, thus affecting high-NFC individuals more than low-NFC individuals, supporting research that shows involvement influences one's information processing in an online setting (Wang et al., 2009).

For managers, the results provide a banner ad strategy for consumers who wade deeper into a web site. Because both high- and low-NFC consumers recalled product-type ads at a 
greater rate than they did brand-type ads after repetition, it would be wise for marketers to move from brand-type ads in the first page or two of a web site to more product-type the more frequently a consumer clicks on new pages in the site. Taken in combination with the results of Study 1, it would make strategic sense to place a brand-type ad on the home page, and then begin repetition of product-type banner ads on subsequent pages a consumer visits.

\section{Study 3: consumer propensity to recall banner ads with directives}

It has been shown that message directives or promotions in online ads affect recall (Chatterjee, 2005; Yaveroglu and Donthu, 2008). Study 3 expands on those findings and tests whether specific types of banner ads are more highly recalled by individuals based on their NFC. In doing so, Study 3 tests H5 and H6.

\section{Study 3: participants}

An online questionnaire was completed by 130 respondents, of which 84 were female ( 64.6 percent) and the age range was 19 to $43(M=24.13)$. Responses were gathered online from undergraduate students at a university in the Southwest United States in exchange for course extra credit.

\section{Study 3: procedure}

Following the same methodology as the first two studies and previous research (Drèze and Hussherr, 2003), advertisement recall (dependent variable) was measured in unaided, partially aided, and fully aided situations. NFC and ad type (independent variables) were manipulated as they were in the first two studies. However, Study 3 was more akin to Study 1 in that participants saw three different banner ads (Nike, Apple, Lexus) that were either product-type or brandtype. This time, though, a new set of product-based ads were created that included the phrase "CLICK HERE to Win one FREE!" as a directive-based promotional element similar to previous efforts (Danaher and Mullarkey, 2003). As in Study 1 , one banner ad of each company was placed on top of each page, meaning that respondents only saw one banner ad for each company one time. The combination of web page and banner ad was randomized so that participants saw banner ads in random order, and participants only saw either brandbased or product-based ads only.

As was the case in the first two studies, a 2 (ad type: brand vs product) $\times 2$ (NFC: high vs low) between-subjects fullfactorial design was implemented in which participants were again given a cover story that the intent of the study was to evaluate online news sites, and were asked to read the same initial paragraph before proceeding. After seeing the web pages with the banner ads, respondents were asked a series of reading comprehension questions about the news story, then saw the same filler questions as previous studies before completing the NFC scale and the recall measures. Attitude toward the brands was measured and demographics captured.

\section{Study 3: results}

With 125 respondents (96.2 percent) answering the first reading comprehension question correctly, 105 (80.8 percent) answering the second correctly, and 31 (23.8 percent) answering the third correctly, the simulation placed them in a situation that mirrored reality. Similar to the previous studies, NFC ( $\alpha=.853)$, ATB $_{\text {Apple }}(\alpha=0.907)$, ATB $_{\text {Lexus }}$ $(\alpha=0.923)$ and $\mathrm{ATB}_{\text {Nike }}(\alpha=0.906)$ demonstrated high reliability (Hair et al., 2006), and results of the dependent variables were analyzed using full factorial, between-subjects MANCOVA with a median split performed to divide participants into high and low NFC groups $(M=4.673$, $M d n=4.667)$. Recall was based on the raw scores of how many of the three advertisements respondents recalled accurately for unaided, partially aided, and fully aided recall, along with a recall total per participant.

As was the case in the second study but not the first, recall overall was not significant for the main effect nor the interaction ( $p$ s $>0.10$ ). However, as predicted by H5, lowNFC consumers did recall product-type ads with the directive message at a greater rate than high-NFC consumers $\left(M_{\text {high }}=4.159, M_{\text {low }}=4.607\right)$. In addition, high-NFC consumers recalled brand-type ads at a greater rate than low-NFC consumers $\left(M_{\text {high }}=4.636 \quad M_{\text {low }}=4.428\right)$, and high-NFC consumers recalled brand-type ads at a greater rate than low-NFC consumers recalled product type ads $\left(M_{\text {high }}=4.636, M_{\text {low }}=4.607\right)$. Despite results moving in the direction posited by the hypotheses, neither was significant. Likewise, there were no significant results in the betweensubjects tests (all ps $>0.10$ ), nor was the covariate (ATB) significant. To test H6, an independent-samples T-test was conducted on high-NFC consumers who saw the brand-type banner ads, and low-NFC consumers who saw the producttype ads. While means for the two groups provided directional support for $H 6$, results for each of the recall situations were not significant.

\section{Study 3: discussion}

This study provides support for previous research (Danaher and Mullarkey, 2003; Hupfer and Grey, 2005) that directive messaging in online ads can affect recall, and identifies specific banner ad directive content (i.e. "click here" and "win one free") as being less appealing to high-NFC individuals, lending credence to the idea that these directives do not support the message argument. For the first time, individuals low in NFC recalled a product banner ad more readily than those seeking more information (high-NFC consumers), providing additional message strategies and opportunities for marketing managers that will be discussed in the implications. The findings that high-NFC consumers recalled banner ads more readily than directive-based product ads may also confirm that arguments in advertising messages must be high in quality (Cacioppo et al., 1983) to attract the attention of more cognitively based individuals.

In addition, direction of the means for high-NFC consumers and brand-type ad recall compared to low-NFC consumers and product-type ad recall does lend additional credence to the results of Study 1 that suggested ads on a homepage should be brand-focused. But because recall by high-NFC individuals, who have an inherent propensity to seek more information, was the lowest among the four combinations of NFC and ad type, banner ads with directives may be a poor online advertising strategy for targeting consumers who click on multiple pages on a web site. 


\section{Conclusions and implications}

The research contributes to the literature on advertising strategies in an online environment by demonstrating that consumers process banner ads designed for products and brands differently. By doing so, it extends ELM to an online setting, and provides some evidence that brand-type ads may be a preferred strategy based on overall recall. These results have implications for both researchers and marketing managers. For academics, this research effort establishes that, for the first time, need for cognition has an effect on banner advertisement recall. More importantly, the results show that, overall, individuals who aspire to more cognitive efforts in information processing pay closer attention to banner ads that feature product-based arguments, while those who do not need extensive cognitive processing pay more attention to advertisements that reinforce the brand.

However, because this was the first effort to tie NFC to banner ad type, more research is needed to examine the variety of banner ads as well as other online ads in the context of ELM and an individual's need for cognition. Researchers may also want to examine this relationship of NFC and online ad type via different measurements. For example, while traditional metrics can be used to measure brand awareness through online advertising, research using implicit memory measures shows that long-term ad exposure effects, and exposure-induced affective or behavioral predispositions, compliment the shortcomings of traditional measures such as recall, recognition and CTR, particularly when consumers are not engaged in processing the advertisements (Yoo, 2007). Future research on ad type (product vs brand) should therefore be conducted examining the implicit memory of consumers.

For marketing managers, the results provide some support that positive brand images can be developed without consumers clicking on the ad (Yoo, 2009), therefore giving managers opportunities for revising or creating new online advertising strategies. Though not statistically significant, because high-NFC consumers recall product-type ads at a slightly greater rate than low-NFC consumers, managers may still consider tying their product-type ads to amount of information or time a consumer spends on a web site. For example, product-type ads would capture more attention the deeper a consumer goes into the site and on pages whose content is information-oriented. In addition, because highNFC consumers recalled brand-type ads at a greater rate than low-NFC consumers recalled product-type ads, marketing strategy and the results of Study 1 and Study 3 would suggest that brand-type ads on a homepage or secondary page would affect recall for more consumers than a product-type ad. Taken in concert with the results of Study 2, marketing managers would be wise to generate repeated exposures of product-type ads the more pages a consumer clicks on a web site. Finally, like previous research (Chtourou et al., 2002; Rettie et al., 2004), the results lend some credence to the idea that incentives had little effect on banner ad recall and may therefore be a piece of the online banner ad strategy that can be eliminated from the marketing mix.

With marketers adopting targeted advertisements in which consumers are shown ads based on past behaviors, including information searched for, web sites visited, and purchases made (BusinessWeek, 2007), the results provide opportunities for practitioners to develop dynamic online advertising strategies. Knowing that high-NFC consumers recall product-type ads at a greater rate than brand-type ads, managers can appropriately change the type of ads to which they expose consumers based on the number of web pages an individual click through on their site, or based on the amount of time an individual spends on the site. As pages visited or time spent increases, web sites should move from more brandbased advertising to more product-based advertising, knowing that these consumers are seeking additional information. Marketing managers can also partner with online retailers who capture consumer information, such as Amazon.com, that enables them to greet returning visitors, so that more of the firm's product-oriented or brand-oriented banner ads could populate the web pages when specific customers return in the future. Finally, a holistic review of an online advertising strategy should be considered by marketing managers in light of these results. For some, a brand-reinforcement strategy may be the most appropriate use of their online marketing budget, particularly if the placement of such ads is on web sites that have a limited visitation rate, such as search engine pages that are simply an intermediary for the consumer to reach the destination that actually provides the information for which they are searching. Conversely, marketing managers may take a more product-oriented strategy if their media buy is closely associated with web sites in which individuals are known to visit for longer periods of time and view more pages, such as travel and vacation sites.

\section{Limitations}

As mentioned in the methodology discussion, elements including web site complexity, style, and content, as well as duration of a consumer's visit to a site can affect content recall, making design of the web site used in this research a limitation. Though the intent of the research was to study recall of the banner ads specifically, other elements were not controlled. However, attempts to limit the potential effects of these variables was taken into consideration by randomizing only the banner ad for each participant, and changing only the news story of the web sites as users moved through the three pages to continue reading the story. The static nature of the web pages did not allow respondents to click on the banner ads, thus eliminating the opportunity to evaluate CTR as a measurement for advertisement effectiveness. Also, participants were unable to return to a previous web page during the simulation aspect of the study - a feature normally found in the online environment that can enhance advertisement effectiveness.

The use of Lexus as one of the three brands is a possible limitation because it is a division of Toyota Motor Corporation, which itself was 8th on the top 100 list (Interbrand, 2010), and the initial paragraph and web site news story featured Toyota's automobile recall. However, Lexus maintains separate marketing efforts from Toyota, a strategy that was conceived with the debut of the Lexus in 1989, and Toyota Motor Corporation keeps the two corporate elements separate from one another (Toyota Motor Corporation, 2011). For example, Lexus maintains a separate brand and logo to distinguish itself from its parent company (Toyota Motor Corporation, 2011), and operates separate dealerships (Segal, 2006). Because some Lexus models were recalled by Toyota in 2010, it is possible that some participants had an increased awareness of the brand 
and could therefore play a subconscious role in recalling the banner ads. Likewise, because Apple had pushed back the release of the iPad in January 2010, two months prior to initiation of data collection, participants could have had a subconscious awareness of that company, which could likewise influence recall. However, attitude toward the brand was not found to be significant in two of the three studies, and was accounted for as a covariate in all three.

The three ads also were not pre-tested to determine if consumers consider one to be more product focused and the other to be more brand focused. However, neither consumer interpretation of the ads nor consumer involvement with the brand or product was the focus of the research. Rather, this research investigated consumer recall of banner ads through high- or low-involvement with the message in the advertisement using the need for cognition (NFC) scale. Finally, recall methodology is always subject to researcher bias in the evaluation of qualification for acceptable recording of accurate or inaccurate recall response. Because visitors to a web site in goal-directed mode are less likely to recall banner ads than those just surfing (Danaher and Mullarkey, 2003), it is possible future research should take that into account.

\section{References}

Abimbola, T. (2009), "Brand, organisation identity and reputation: bold approaches to big challenges", fournal of Brand Management, Vol. 16 No. 4, pp. 219-20.

Baker, M.J. and Balmer, J.M.T. (1997), "Visual identity: trappings or substance?", European fournal of Marketing, Vol. 31 Nos 5/6, pp. 366-82.

Baltas, G. (2003), "Determinants of internet advertising effectiveness: an empirical study", International fournal of Market Research, Vol. 45 No. 4, pp. 505-13.

Barron, R.M. and Kenny, D.A. (1986), "The moderatormediator variable distinction in social psychological research: conceptual, strategic, and statistical considerations", fournal of Personality and Social Psvchologv, Vol. 51 No. 6, pp. 1173-82.

Briggs, R. and Hollis, N. (1997), "Advertising on the web: is there response before click-through?", fournal of Advertising Research, Vol. 37, March/April, pp. 33-45.

Broussard, G. (2000), "How advertising frequency can work to build online advertising effectiveness", International fournal of Market Research, Vol. 42 No. 4, pp. 439-57.

Burke, R.R. and Srull, T.K. (1988), "Competitive interference and consumer memory for advertising", fournal of Consumer Research, Vol. 15, June, pp. 55-68.

BusinessWeek (2007), "So many ads, so few clicks: can more targeted pitches on Facebook and other sites reverse the shrinking response to online ads?", available at: www.b usinessweek.com/magazine/content/07_46/b4058053.htm (accessed March 17, 2010).

Cacioppo, J.T. and Petty, R.E. (1979), "Effects of message repetition and position on cognitive response, recall, and persuasion", Zournal of Personality and Social Psychology, Vol. 37, pp. 97-109.

Cacioppo, J.T. and Petty, R.E. (1980), "The need for cognition", Fournal of Personalitv and Social Psvchology, Vol. 42 No. 1, pp. 116-31.

Cacioppo, J.T., Petty, R.E. and Kao, C.F. (1984), "The efficient assessment of need for cognition", fournal of Personalitv Assessment, Vol. 48 No. 3, p. 306.
Cacioppo, J.T., Petty, R.E. and Morris, K.J. (1983), "Effects of need for cognition on message evaluation, recall, and persuasion", fournal of Personality and Social Psychology, Vol. 45 No. 4, pp. 805-18.

Cacioppo, J.T., Petty, R.E., Feinstein, J.A. and Jarvis, W.B.G. (1996), "Dispositional differences in cognitive motivation: the life and times of individuals varying in need for cognition", Psychological Bulletin, Vol. 119 No. 2, pp. 197-253.

Chandon, J., Chtourou, M. and Fortin, D. (2003), "Effects of configuration and exposure levels on responses to web advertisements", fournal of Advertising Research, Vol. 43 No. 2, pp. 217-29.

Chatterjee, P. (2005), "Changing banner ad executions on the web: impact on clickthroughs and communication outcomes", Advances in Consumer Research, Vol. 32, pp. 51-7.

Chatterjee, P., Hoffman, D.L. and Novak, T.P. (2003), "Modeling the clickstream: implications for web-based advertising efforts", Marketing Science, Vol. 22 No. 4, pp. 520-41.

Cho, C.H. (2003), "Factors influencing clicking of banner ads on the WWW", CuberPsychology \& Behavior, Vol. 6 No. 2, pp. 201-15.

Chtourou, M.S., Chandon, J.L. and Zollinger, M. (2002), "Effect of price information and promotion on clickthrough rate for internet banners", fournal of Euromarketing, Vol. 11 No. 20, pp. 23-40.

Cialdini, R., Petty, R.E. and Cacioppo, J.T. (1981), “Attitude and attitude change", Annual Review of Psychologv, Vol. 32, p. 366.

Cohen, A., Stotland, E. and Wolfe, D. (1955), "An experimental investigation of need for cognition", The fournal of Abnormal and Social Psvchologv, Vol. 51 No. 2, pp. 291-4.

Danaher, P.J. and Mullarkey, G.W. (2003), "Factors affecting online advertising recall: a study of students", fournal of Advertising Research, Vol. 43 No. 3, pp. 252-67.

Dowling, G.R. (1994), Corporate Reputations: Strategies for Developing the Corporate Brand, Kogan Page, London.

Drèze, X. and Hussherr, F.X. (2003), "Internet advertising: is anybody watching?", fournal of Interactive Marketing, Vol. 17 No. 4, pp. 8-23.

Goodrich, K. (2011), "Anarchy of effects? Exploring attention to online advertising and multiple outcomes", Psychology \& Marketing, Vol. 28 No. 4, pp. 417-40.

Hair, J.F., Black, W.C., Babin, B.J., Anderson, R.E. and Tatham, R.L. (2006), Multivariate Data Analysis, Pearson Prentice Hall, Englewood Cliffs, NJ.

Haugtvedt, C.P. and Petty, R.E. (1992), "Personality and persuasion: need for cognition moderates the persistence and resistance of attitude changes", fournal of Personality E Social Psychologv, Vol. 63 No. 2, pp. 308-19.

Haugtvedt, C.P., Petty, R.E. and Cacioppo, J.T. (1992), "Need for cognition and advertising: understanding the role of personality variables in consumer behavior", fournal of Consumer Psychology, Vol. 1 No. 3, pp. 239-60.

Henderson, P.W. and Cote, J.A. (1998), "Guidelines for selecting or modifying logos", Zournal of Marketing, Vol. 62 No. 2, pp. 14-30.

Hollis, N. (2005), "Ten years of learning on how online advertising builds brands", fournal of Advertising Research, Vol. 45 No. 2, pp. 255-68. 
Hong, W., Thong, J.Y.L. and Tam, K.Y. (2004), "Does animation attract online user's attention? The effects of Flash on information search performance and perceptions", Information Sustems Research, Vol. 15 No. 1, pp. 60-86.

Hupfer, M.E. and Grey, A. (2005), "Getting something for nothing: the impact of a sample offer and user mode on banner ad response", fournal of Interactive Advertising, Vol. 6 No. 1, pp. 149-54.

Interbrand (2010), Best Global Brands 2010, available at: www.interbrand.com/Libraries/Branding_Studies/Best_ Global_Brands_2009.sflb.ashx (accessed 21 March 2010).

Krugman, H.E. (1972), "Why three exposures may be enough", fournal of Advertising Research, Vol. 12 No. 6, pp. 11-14.

Luk, S.T.K., Chan, W.P.S. and Li, E.L.Y. (2002), "The content of internet advertisements and its impact on awareness and selling performance", Zournal of Marketing Management, Vol. 18, pp. 693-719.

McCoy, S., Everard, A., Polak, P. and Galletta, D.F. (2008), "An experimental study of antecedents and consequences of online ad intrusiveness", International fournal of HumanComputer Interaction, Vol. 24 No. 7, pp. 672-99.

MacInnis, D.J., Shapiro, S. and Mani, G. (1999), "Enhancing brand awareness through brand symbols", Advances in Consumer Research, Vol. 26, pp. 601-8.

Mininni, T. (2005), "Marketing metrics and package design", available at: www.brandchannel.com/brand_speak.asp?bs_ id=117 (accessed 27 March 2010).

Olins, W. (1989), Corporate Identity, Thames and Hudson, London.

Peltier, J.W. and Schibrowsky, J.A. (1994), "Need for cognition, advertisement viewing time and memory for advertising stimuli”, Advances in Consumer Research, Vol. 21 No. 1, pp. 244-50.

Peracchio, L.A. and Meyers-Levy, J. (1994), "How ambiguous cropped objects in ad photos can affect product evaluations", Zournal of Consumer Research, Vol. 21 No. 1, pp. 190-204.

Pérez-Gladish, B., Gonzalez, I., Bilbao-Terol, A. and Arenas-Parra, M. (2010), "Planning a TV advertising campaign: a Crip multiobjective programming model from fuzzy basic data", Omega, Vol. 38 Nos 1/2, pp. 84-94.

Petty, R.E. and Cacioppo, J.T. (1981), Attitudes and Persuasion: Classic and Contemporary Approaches, William C. Brown, Dubuque, IA.

Petty, R.E., Cacioppo, J.T. and Schumann, D. (1983), "Central and peripheral routes to advertising effectiveness: the moderating role of involvement", fournal of Consumer Research, Vol. 10, September, pp. 135-46.

Pharr, J.M. (2004), "A research agenda for brand-building on the internet with banner advertising", Services Marketing Ouarterlv, Vol. 26 No. 2, pp. 39-47.

Pieters, R. and Warlop, L. (1999), "Visual attention during brand choice: the impact of time pressure and task motivation", International fournal of Research in Marketing, Vol. 16, pp. 1-17.

Rettie, R., Grandcolas, U. and McNeil, C. (2004), "Post impressions: internet advertising without click-through", paper presented at the Academy of Marketing Annual Conference 2004, 6-9 July, Cheltenham.

Robinson, H., Wysocka, A. and Hand, C. (2007), "Internet advertising effectiveness: the effect of design and click- through rates for banner ads", International fournal of Advertising, Vol. 26 No. 4, pp. 527-41.

Rodgers, S. and Sheldon, K.M. (2002), "An improved way to characterize internet users", fournal of Advertising Research, Vol. 42 No. 5, pp. 85-94.

Segal, B. (2006), "Designing a brand strategy: How to get recognized and stay recognized in a noisy world", available at: http://ezinearticles.com/?Designing-a-Brand-Strategy-How-to-Get-Recognized-and-Stay-Recognized-in-a-NoisyWorld\&id=785619 (accessed 10 February 2010).

Toyota Motor Corporation (2011), Annual Report 2010: Purpose, Perspective and Passion, available at: www.toyotaglobal.com/investors/ir_library/ (accessed 21 October 2010).

Tsao, W.C. (2010), "Investigating brand attitude changes toward high-involved hedonic products via optimal ad appeal arrangements over multiple exposures", International fournal of Management, Vol. 27 No. 3, pp. 511-27.

Unnava, H.R. and Burnkrant, R.E. (2005), "Effects of repeating varied ad executions on brand name memory", fournal of Marketing Research, Vol. 28 No. 4, pp. 406-16.

Wang, K., Wang, E.T.G. and Farn, C.K. (2009), "Influence of web advertising strategies, consumer goal-directedness, and consumer involvement on web advertising effectiveness", International fournal of Electronic Commerce, Vol. 13 No. 4, pp. 67-95.

Yaveroglu, I. and Donthu, N. (2008), "Advertising repetition and placement issues in on-line environments", fournal of Advertising, Vol. 37 No. 2, pp. 31-43.

Yoo, C.Y. (2007), "Implicit memory measures for web advertising effectiveness", fournalism \& Mass Communication Ouarterlv, Vol. 84 No. 1, pp. 7-23.

Yoo, C.Y. (2009), "Effects beyond click-through: incidental exposure to web advertising", fournal of Marketing Communications, Vol. 15 No. 4, pp. 227-46.

Yoo, C.Y. and Kim, K. (2005), "Processing of animation in online banner advertising: the roles of cognitive and emotional responses", fournal of Interactive Marketing, Vol. 19 No. 4, pp. 18-34.

\section{About the author}

Eric Van Steenburg is a $\mathrm{PhD}$ candidate at the University of North Texas, Denton. His research interests are persuasive communications, consumer behavior, nonprofit marketing, and political marketing. He has published in Fournal of Brand Management, Fournal of Political Marketing, Fournal of Promotion Management, and numerous conference proceedings including the American Marketing Association, the Academy of Marketing Science, and the Society for Marketing Advances. Previously, he was Executive Director for a nonprofit organization, and Adjunct Lecturer at Southern Methodist University. Eric Van Steenburg can be contacted at: eric.vansteenburg@unt.edu

\section{Executive summary and implications for managers and executives}

This summary has been provided to allow managers and executives a rapid appreciation of the content of this article. Those with a particular interest in the topic covered may then read the article in toto to take advantage of the more comprehensive description of the research undertaken and its results to get the full benefits of the material present. 
Two accepted aims for online marketing are brand awareness and brand recognition. Marketers are, however, divided on how online advertisements should be measured. One side of the argument considers click-through-rate (CTR) as the best indicator of an ad's effectiveness. Others believe it possible to develop recognition and awareness without the banner being clicked on. Their view is that recall of the message as a measurement tool is a viable alternative. Some academics have discovered that recall and recognition positively impact on both consumer attention to an ad and their buying intention.

A key advantage of using CTR to measure banner ad effectiveness is its ability to capture "voluntary behavior in a realistic environment". However, any lack of appropriate CTRs means that data can be unreliable. The alternative view advocates the use of different metrics when the aim is "more traditional brand building".

According to some scholars, firms should connect with branding activities which have successfully positioned brands and their images into consumer minds. Brand images inspire recall of the cue from memory and the suggestion is that online banner ads should function in a similar vein. By leveraging current brand images as a prompt to online brand advertising, marketers can increase customer recall of online ads which serve to promote the brand. It has been observed though that awareness of online ads is affected when images of products are used.

Certain theorists posit that persuasive information is processed differently by people. It depends on context, consumer characteristics and message content as to whether individuals take the central or peripheral route. In addition, choice is determined by level of involvement. Highly involved individuals scrutinize message content more closely than those whose involvement is low. Response to the information with high involvement processing depends on how the information relates to the individuals existing attitudes and beliefs. Whether the communication is high or low can also govern which persuasive advertising forms are likely to work best.

Scholars similarly point to need for cognition (NFC) as a means to predict consumer behavior. The construct reflects among other things the degree to which individuals engage in problem-solving behaviors. As with involvement, people with high NFC tendencies desire more information than when NFC is low. The central processing route is chosen by high NFC consumers who scrutinize message detail and complexity. Evidence shows that message persuasiveness, message recall and the effectiveness of online advertisement are also influenced by NFC.

The current study is founded on an assumption that high NFC consumers are more attracted to product-related ads because of their greater message complexity. High NFC is also likely to prompt more cognitive processing when involvement with the message is greater. Conversely, the "more simplistic message" typical of brand ads increases their appeal to low HFC individuals. Studies have confirmed the importance of ad type so its interaction with NFC could determine recall of online advertisements. This detailed processing may even extend to banner ads where such consumers are concerned.

Recall, recognition and click-through intention increases with repeated exposure to the same banner ads, different academics have found. In some cases, however, negative responses can arise with exposure overkill. Individuals likewise respond differently to different components of banner ads, such as promotional offers and directives. Whether directives are processed centrally or peripherally has not been established though. One view is that directives are not part of the ad, so will be processed peripherally and subject to recall by low NFC individuals. Directives do not contribute to any argument, the quality of which has been found to increase recall when NFC is high. It is further claimed that peripheral processing of directives means that low NFC consumers will pay less attention to directives than high NFC individuals will to brand-related ads.

Van Steenberg conducts three studies to explore these issues further. In each study, different samples of university students were exposed to web pages containing a news story. They were told the purpose was to evaluate online news sites. Each page contained either product or brand banner ads relating to Apple, Nike or Lexus. In the first and third study, subjects saw each ad only once. As the second study measured repetition, the same ad appeared on each web page. Banner ads in study three contained directives. To test recall, participants were later exposed to the banner ads in isolation. Reading comprehension questions were included in the survey in order to measure NFC levels.

Among the findings from these studies are:

- A minimal number of cues were needed to enable subjects rating high in NFC to recall complex messages.

- Low NFC individuals more readily recall brand-related online advertisements when provided with more cues to the ad.

- Recall of product-type ads was greater among high NFC consumers than among low NFC individuals.

- Following repetition, recall was greater for product-related ads than for brand-related ads among both NFC types.

- High NFC consumers recall brand-type ads better than low NFC consumers when repeatedly viewing the same ad.

- Banner ads were recalled more easily than directive-based product ads by consumers rating high in NFC.

- The variables NFC and ad type exhibited a combined rather than independent impact on recall.

Evidence here indicates that practitioners should implement a strategy whereby consumer intensity to engage in cognitive activity is coordinated with an appropriate type of banner advertisement. The author suggests placing a brand-type ad on the home age of the company web site to increase recall, particularly among individuals less inclined towards extensive information processing. Product-type banner ads could then be repeatedly used as the consumer visits more pages and goes deeper into the site. The premise is that such individuals will be seeking detailed information and therefore be higher in NFC. As previous studies have argued though, it is essential that advertising messages present quality arguments in order to stimulate interest among such consumers.

In the opinion of Van Steenberg, it is possible for marketers to liaise with online retailers to acquire information about consumer behavior online. Knowledge of time spent on a web site or the number of pages visited could enable customization so that appropriate ad types are displayed when specific customers make future revisits. Whether managers adopt a strategy that is brand or product oriented may also depend on 
what the web site provides. The author cites search engines as an example where a focus on the brand is more relevant because such sites function as "intermediaries" on the way to the user's intended destination. Product-type ads are viewed as appropriate on such as travel and vacation web sites where consumers will spend a longer time, visit more pages and conduct a wider information search.

It is acknowledged by Van Steenberg that certain events which attracted publicity could have increased subject consciousness of two of the brands used and possibly influenced recall. Returning to previous pages can improve the effectiveness of advertisements, but that provision was not offered in this simulation. Further investigations should also consider that recall can be influenced by web site design features including style, complexity and content. Another idea is to compare "goal-directed" web site visits with surfing and measure how consumers determine whether an ad is brandrelated or product-related.

( $A$ précis of the article "Consumer recall of brand versus product banner ads”. Supplied by Marketing Consultants for Emerald.) 